\title{
TWO NEW SPECIES OF PSEUDOTYRANNOCHTHONIIDAE, INCLUDING THE FIRST SPECIES OF PSEUDOTYRANNOCHTHONIUS (PSEUDOSCORPIONES) FROM CHINA
}

\author{
Zhizhong GaO, Yanfen Zhang and Feng Zhang* \\ College of Life Sciences, Hebei University, Baoding, Hebei 071002, China \\ E-mail: gaozhizhong1987@126.com; *corresponding author:dudu06042001@163.com
}

Two new pseudoscorpion species, Pseudotyrannochthonius cheni sp. n. and Allochthonius (A.) fanjingshan sp. n. (family Pseudotyrannochthoniidae Beier, 1932) are described and illustrated. P. cheni sp. n. represents the first record of this genus from China and is also the first epigean (surface) species to be recorded from eastern Asia because all other species (from Korea and Japan) occur in subterranean habitats. A. (A.) fanjingshan sp. $\mathbf{n}$. is the eighth species in this genus from China and reflects a wider distribution of the genus in this country. Detailed diagnosis, descriptions and illustrations are presented together with distribution maps and some habitat information.

Key words: taxonomy, pseudoscorpion, new species, new record, China.

\section{INTRODUCTION}

The pseudoscorpion family Pseudotyrannochthoniidae Beier, 1932 contains five genera, Afrochthonius Beier, Allochthonius Chamberlin, Centrochthonius Beier, Pseudotyrannochthonius Beier and Selachochthonius Chamberlin. Two of them, Allochthonius and Centrochthonius, have so far been reported from China (Harvey 2013).

The genus Pseudotyrannochthonius was established by BeIER (1930) and is distributed in Australia, America and East Asia (Harvey 2013). It contains 23 species and 5 subspecies, 9 of which are from East Asia (Harms 2013, Harms \& Harvey 2013, Harvey 2013). This genus is diagnosed by having a serrated epistome; carapace distinctly constricted posteriorly; having the coxal blades inserted individually on coxa I and standing in a row; and only 16-18 setae on the carapace and at most $2: 4: 6: 6: 6$ setae on the first five abdominal tergites (Muchmore 1967). To date, Pseudotyrannochthonius species have not reported from China, but they occur in subterranean habitats throughout Japan and South Korea and most of them absent of eyes. Three additional species which mainly collected in a relatively low temperature during the winter or spring have also been recorded from the eastern USA (Benedict \& MALColm 1970).

The genus Allochthonius was established by ChamberLin (1929) and has an East Asian distribution, with totally 27 species reported (China 8, Japan 16 and Korea 3) (Harvey 2013, Zhang \& Zhang 2014). Allochthonius is divided 
into two subgenera, Allochthonius and Urochthonius Morikawa, 1954. The subgenus Allochthonius is composed of 12 species, of them, seven occur in China; the subgenus Urochthonius includes three species (Harver 2013, GaO \& Zhang 2013, Hu \& Zhang 2012, Zhang \& Zhang 2014), two of them occur in Japan and the third was reported from western China.

Fanjingshan National Nature Reserve, located in the northeastern Guizhou Province, Southwest China, and is well known for its rich flora and fauna of plants and wildlife. It was included in the 'Man and Biosphere' Protection Network of UNESCO in 1986 because of its unparalleled biodiversity at similar latitudes. It is one of the best-preserved subtropical forest ecosystems in China.

Several biodiversity surveys have recently been undertaken to explore the diversity of the arthropod fauna in Fanjingshan National Nature Reserve. While examining the pseudoscorpion specimens collected from leaf litter in Mt. Fanjingshan, we found a female specimen has the characters of epistome serrate; carapace strongly constricted posteriorly; two pairs of eyes present; less setae on carapace, trichobothria $i b$ and ist are not the same level on fixed finger; and it was collected from a rather cold and moist habitat which most members of the genus Pseudotyrannochthonius share, we therefore put it in this genus. It is also the first epigean recorded species in this genus, since Guizhou Province is famous for the karst landform, a large amount of caves were found and explored, this new species maybe a dispersed consequence to be found in leaf litter. Pseudotyrannochthonius has not been recorded from China before and the new species is described and illustrated in this paper under the name of $P$. cheni sp. n. We also describe a new Allochthonius species from Mt. Fanjingshan that belongs to Allochthonius. Detailed diagnosis, descriptions and illustrations of the new taxon are presented in this paper.

Nowadays, the genera in Pseudotyrannochthoniidae are not well defined as they currently stand and that a generic revision is absent. The aim of this study is to describe and name two new species of Pseudotyrannochthoniidae; secondly, first report on the genus Pseudotyrannochthonius from China. Hence, deeper research and comprehensive approach are required in the next future to have a review to this family.

\section{MATERIAL AND METHODS}

The specimens were preserved in $85 \%$ alcohol and deposited in the Museum of Hebei University (MHBU), Baoding, China. General morphological examinations were carried out using a Leica M205Astereomicroscope which was also used for the drawings (with a drawing tube). Digital images were taken using a Leica DFC 550 digital camera attached to a Leica M205A stereomicroscope, using the Leica Application Suite Version 4.6.0 software, which was also used for the measurements. Detailed examination was carried out with an Olympus BX53 general optical microscope. Temporary slide mounts were made 
using glycerol. Terminology and measurements follows (CHAMBERLIN 1931), except for the nomenclature of the segments of the pedipalps and legs (HARver 1992), the term "rallum" (for flagellum) (Judson 2007), the term "coxal blades"(for coxal spines)( Harms \& Harver 2013), the nomenclature of chaetotaxy of the pedipalp finger and the trichobothria (HARver 1992). All measurements were given in $\mathrm{mm}$ and taken in dorsal view unless noted otherwise. 10-4-4-2-4 (24) refers to carapacal chaetotaxy: carapace with 24 setae, anterior margin with ten setae and posterior margin with four setae. Images were edited and formatted using Adobe Photoshop CS5. Distribution maps were produced using ESRI ArcGIS 10.2.2 software and edited in Adobe Photoshop CS5.

\section{TAXONOMY}

Family Pseudotyrannochthoniidae Beier, 1932

Genus Pseudotyrannochthonius Beier, 1930

Beier (1930): 207-208, Beier (1932): 70, Morikawa (1960): 104-105, Beier (1966): 285, Muchmore (1967): 134.

\section{Pseudotyrannochthonius cheni sp. n.}

(Figs 1-3)

Type material. Holotype female (Ps.-MHBU-GZ14101201): China, Guizhou Province, Jiangkou County, Fanjingshan National Nature Reserve [27 $\left.54.494^{\prime} \mathrm{N}, 108^{\circ} 41.859^{\prime} \mathrm{E}\right]$, alt. 2214 m, 12 October 2014, Zhizhong Gao leg.

Etymology. The specific name is a patronym in honour of Dr. Huiming Chen who assisted with the field work.

Diagnosis. This species differs from all other Asian species of Pseudotyrannochthonius by the following combination of characters: epistome serrate; carapace strongly constricted posteriorly; two pairs of eyes present; only five coxal blades (otherwise $>5$ ); 16 teeth acute and spaced along the whole movable chelal finger. This new species is most similar to $P$. kobayashi from Japan, but can be distinguished from the latter by the number of setae on the cheliceral palm (6 vs 5), and by the number of coxal blades (at least 7 in P. kobayashii which is also absence of eyes). Based on the presence or absence of eyes, $P$. cheni can be distinguished from P. kubotai, P. dentifer, and P. undecimclavatus (P. cheni with 4 eyes, while others eyes absent). It differs from $P$. utahensis, $P$. incognitus and $P$. gracilis by the acute and spaced teeth along the whole movable chelal finger (all others with less developed teeth).

Description. Carapace, abdomen, chelicerae and palps yellowish brown, other parts pale yellow. 


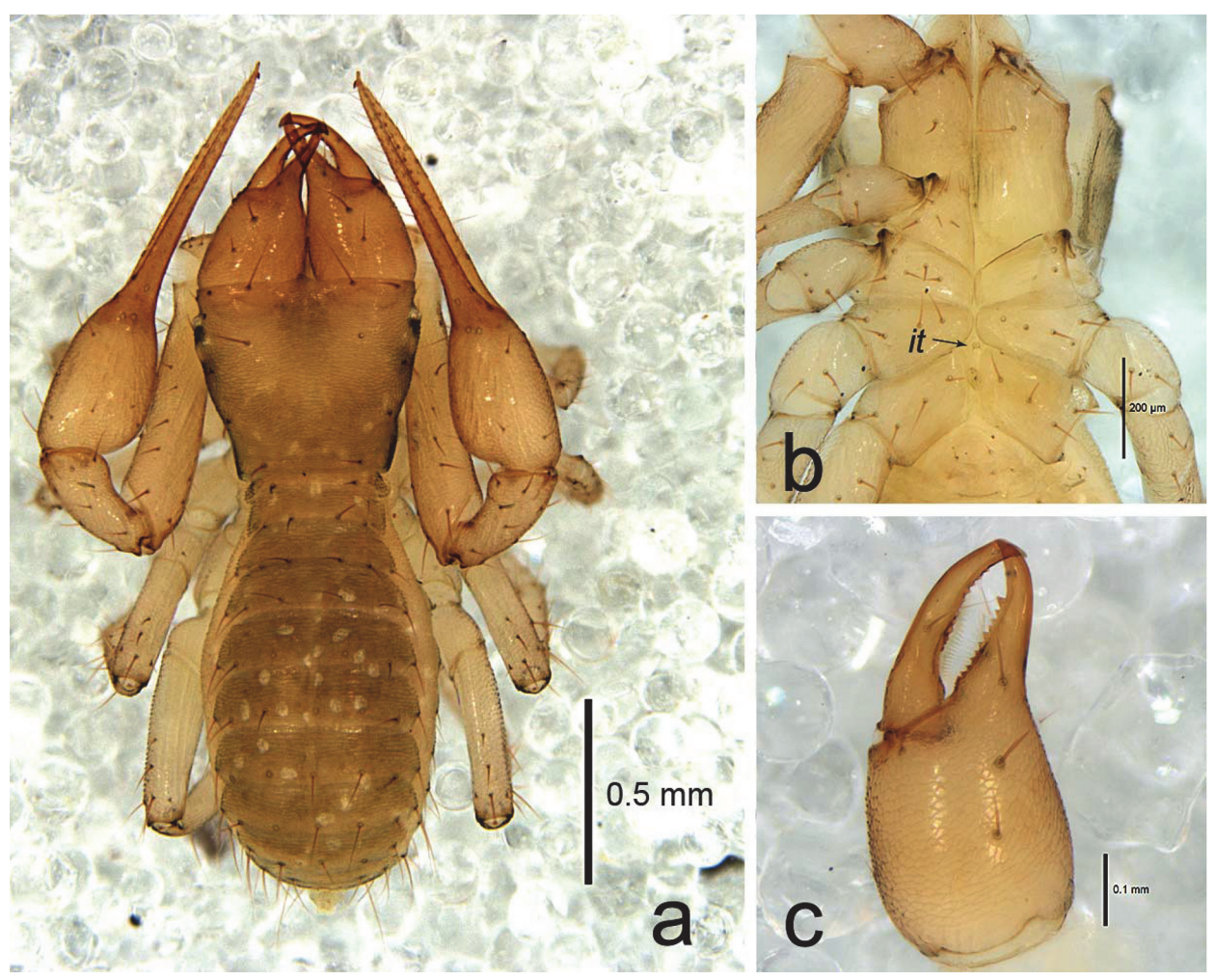

Fig. 1. Pseudotyrannochthonius cheni sp. $\mathrm{n}$. , holotype: $\mathrm{a}=$ habitus, dorsal view; $\mathrm{b}=$ coxae, ventral; it, interoxal tubercle; c = left chelicera, ventrolateral.

Carapace (Fig. 2b) inverted trapezoid; somewhat shorter than broad (0.85 times), strongly constricted posteriorly; anterior eyes with well developed tapeta and situated on tubercles, the posterior ones with rudimentary tapeta only and not situated on tubercles; eyes almost 1/2 diameter from each other, anterior pair of eyes 2 diameters from anterior margin of carapace; epistome present (Fig. 2a) and with some tiny spinules; chaetotaxy: 6-4-2-2-2, 16; with three pairs of lyrifissures, first and second pair between anterior and ocular row of setae, the third pair situated posteriolateral to setae of posterior row.

Coxal area: tip of manducatory process with 2 acuminate distal setae, apical seta straight, about two times longer than subapical seta; pedipalpal coxa with three seta, two at distal margin and one more medial near interior margin, with one medial lyrifissure. Bisetose intercoxal tubercle present, tear dropshaped (Fig. 1b); coxal blades (Fig. 2e) only

Fig. 2. Pseudotyrannochthonius cheni sp. $\mathrm{n}$. , holotype: $\mathrm{a}=$ epistomal process; $\mathrm{b}=$ carapace (dorsal view), position of lyrifissures indicated by black horizontal bars; $c=$ left chelicerae (lateral view); d = tip of cheliceral movable finger (dorsal view); e = coxal blades on leg I (ventral view); $\mathrm{f}=$ left palp (minus chela, dorsal view); $\mathrm{g}=$ left chela (dorsal view); $\mathrm{h}=$ rallum; i = leg I (lateral view); $\mathrm{j}=$ genital area (ventral view), position of lyrifissures indicated by black bars; $\mathrm{k}=$ leg IV (lateral view). Scale bars: $0.25 \mathrm{~mm}(\mathrm{a}-\mathrm{d}, \mathrm{f}-\mathrm{g}, \mathrm{i}-\mathrm{k}) ; 0.20 \mathrm{~mm}(\mathrm{e}, \mathrm{h})$. 


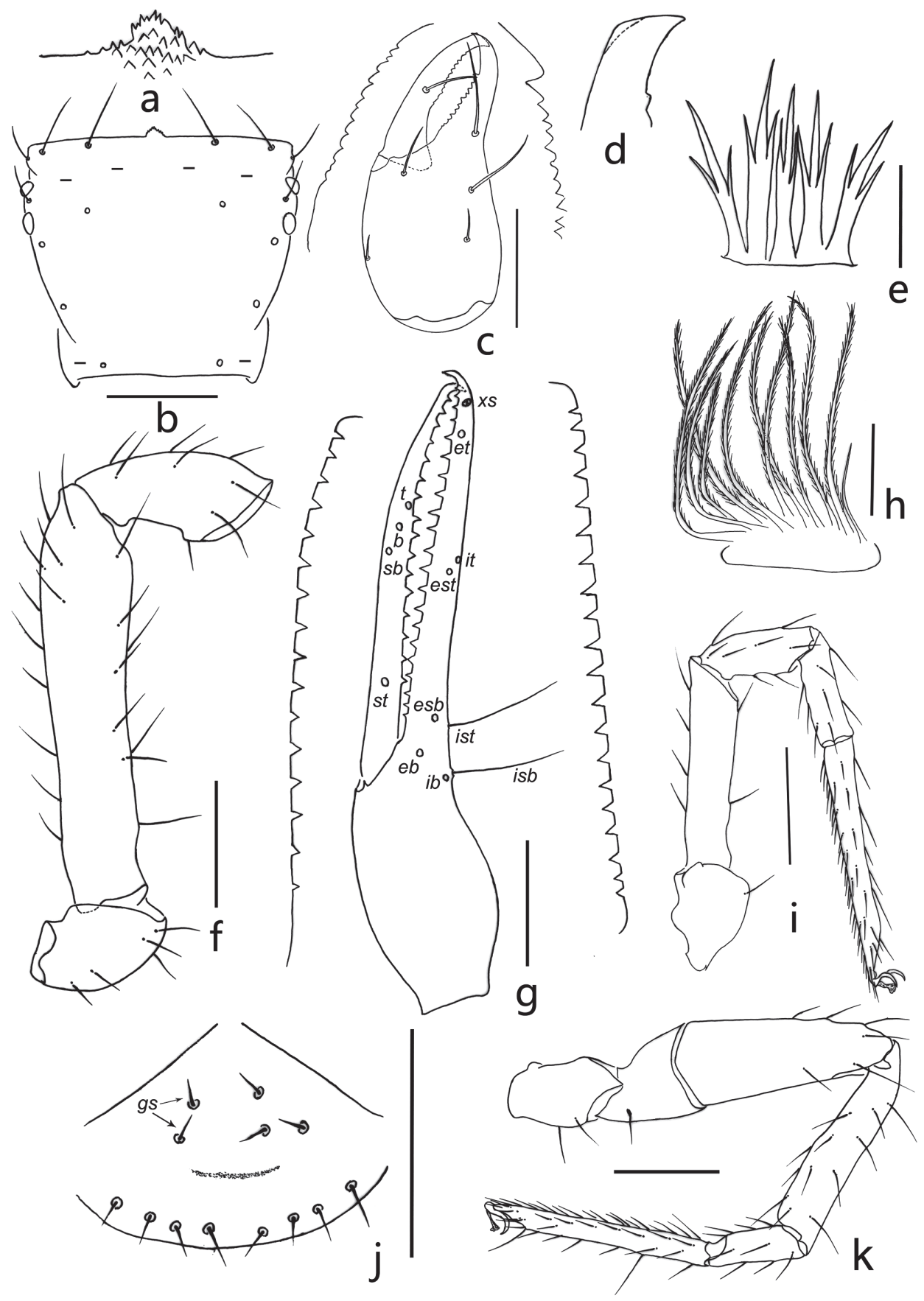




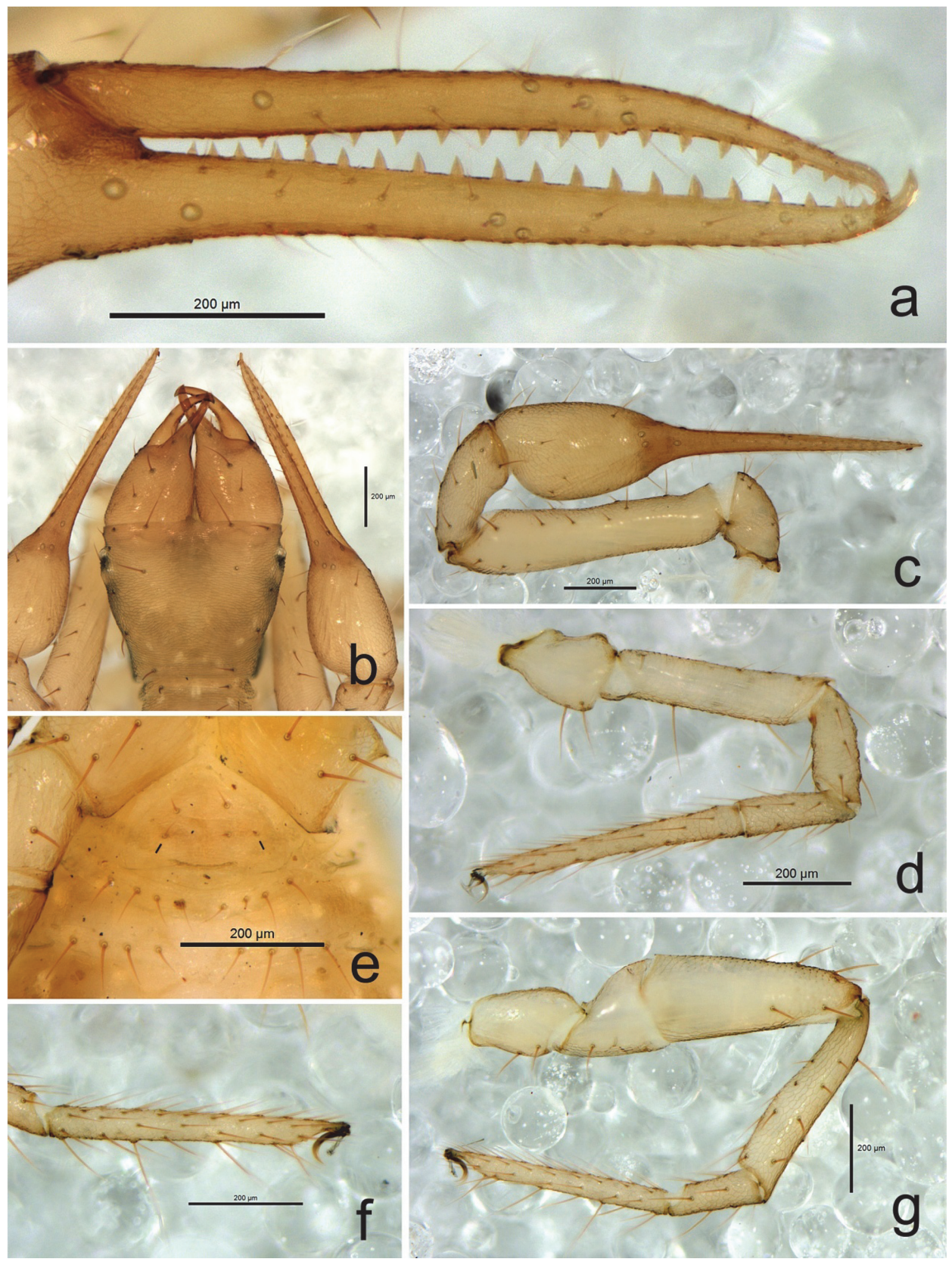

Fig. 3. Pseudotyrannochthonius cheni sp. $\mathrm{n}$. , holotype: $\mathrm{a}=$ left chela; $\mathrm{b}=$ carapace and chelicerae; $\mathrm{c}=$ padipalp; $\mathrm{d}=$ leg I; e = genital area; $\mathrm{f}=$ tarsus of leg IV; $\mathrm{g}=$ leg IV. 
present on coxa I, comprising a transverse, contiguous series of 5 tridentate blades; setae P 3, I 6, II 5, III 5, IV 4 (Fig. 1b).

Chelicera (Fig. 2c): palm with 5 setae, of which a short one is located pro/retrolaterally; slightly shorter than carapace; galeal seta located in middle of movable finger. Fixed finger with 11 conspicuous acute teeth, the apical one large, the others relatively small, one lyrifissures at the base of the fixed finger; tip of movable finger truncated (Fig. 2d) and movable finger with 13 conspicuous acute teeth. Serrula exterior with 15 lamellae; serrula interior with 17 lamellae. Rallum in two rows and composed of 11 blades with fine barbules except the posterior one which is shorter than the others.

Pedipalp (Figs 2f-g; Figs 3a, 3c) mostly with fine reticulations; chelal hand robust; femur 1.54 times longer than carapace; fixed finger with 20 acute teeth, middle ones larger than that in both ends; movable finger with 16 acute teeth. Trichobothria: fixed finger with eight trichobothria, trichobothria $i b$ and is distally on dorsum of palm, $e s b$, ist and $e b$ sublaterally to dorsally at base of fixed chelal finger, $e s b$ close to ist than to $e b$, it and $e s t$ at the middle of fixed finger and forming a pair; et subdistal and duplex $x$ s distal; movable finger with 4 trichobothria, st subproximal and in subbasal position on finger, triplet $s b, b$ and $t$ medial to distomedial, distance between $s b$ and $b$ somewhat equal to the distance between $b$ and $t, s b$ situated subventrally, $b$ medial and $t$ rather subventral; sensilla absent.

Abdomen ovate; tergal chaetotaxy I-XII $: 2: 4: 6: 6: 6: 7: 7: 7: 6: 4:$ TT $: 0$; anterior genital operculum with 5 setae, posterior margin with 8 marginal setae, 13 in total, two oblique lyrifissures present anterolateral to genital opening; sternal chaetotaxy III-X : 16 : $12: 12: 11: 11: 10: 8: 4$.

Legs (Figs 2i, 2k; Figs 3d, 3g, 3f) typical of family. Leg I and IV with reticulations. Leg IV with a long tactile seta on tarsus (TS $=0.28)$.

Measurements (length/breadth or depth in mm, ratios in parentheses). Female. Body length 1.68. Carapace $0.52 \times 0.61$ (0.85). Palpal trochanter $0.25 \times 0.17(1.47)$, femur $0.80 \times$ $0.18(4.44)$, patella $0.37 \times 0.17(2.18)$, chela $1.21 \times 0.26(4.65)$, palm $0.46 \times 0.26(1.77)$, movable finger length $0.78(1.70 \times$ palm) . Leg I trochanter $0.18 \times 0.14(1.29)$, femur $0.45 \times 0.09(5.00)$, patella $0.28 \times 0.08(3.50)$, tibia $0.24 \times 0.07(3.43)$, tarsus $053 \times 0.06(8.83)$; leg IV trochanter $0.26 \times 0.16(1.63)$, femur+patella $0.70 \times 0.21(3.33)$, tibia $0.52 \times 0.11(4.73)$, metatarsus $0.21 \times$ $0.08(2.63)$, tarsus $0.53 \times 0.06(8.83)$.

Distribution. Currently known only from the type locality, Guizhou Province, China.

Habitat and ecology. Pseudotyrannochthonius cheni sp. n. was collected from the bush leaf litter, there is a kind of bamboo around and the leaf litter is extremely moist; since the high altitude and collection time in late autumn, the air temperature is very low, it seems that species in Pseudotyrannochthonius are mostly psychrophilic.

\section{Genus Allochthonius Chamberlin, 1929}

Subgenus Allochthonius (Allochthonius) Chamberlin, 1929

Beier (1932): 61-62, Morikawa (1960): 98, Hu \& Zhang (2011): 2168-2169, Hu \& Zhang (2012): 243-248, GAO \& ZHANG (2013): 107-112. 


\section{Allochthonius (Allochthonius) fanjingshan sp. n.}

(Figs 4-7)

Type material. Holotype male (Ps.-MHBU-GZ14101202): China, Guizhou Province, Jiangkou County, Fanjingshan National Nature Reserve [27 $\left.54.486^{\prime} \mathrm{N}, 108^{\circ} 41.843^{\prime} \mathrm{E}\right]$, alt. 2210 m, 12 October 2014, Zhizhong Gao leg. Paratypes: two females (Ps.-MHBU-GZ14101203-04), same data as holotype.

Etymology. The specific name is a noun in apposition taken from to the type locality.

Diagnosis. This new species differs from all other species of the genus by the following combination of characters: epistome absent; palm of chelicera with fine granulations; coxal blades all situated on a common tubercle; sternites III-VI with pale color area; male pedipalpal femur 5.32 (female 5.52-5.95) times longer than broad; male chela 5.03 (female 4.00-4.15) times longer than broad. Chaetotaxy of carapace: 8-6-6-2-4, 26.

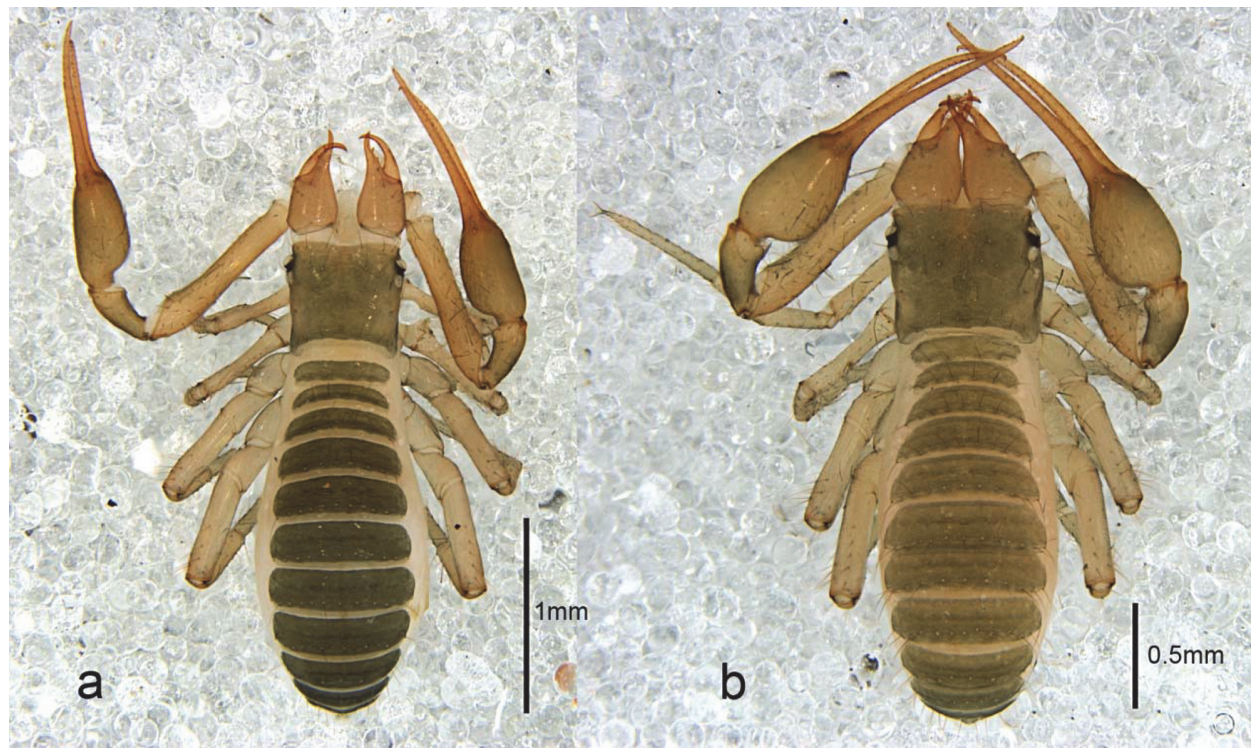

Fig. 4. Allochthonius (Allochthonius) fanjingshan sp. n., habitus: a = dorsal view of holotype; $\mathrm{b}=$ dorsal view of female paratype (Ps.-MHBU-GZ14101203).

Fig. 5. Allochthonius (Allochthonius) fanjingshan sp. n., holotype except b: a = carapace (dorsal view); $b=$ carapace of female paratype (dorsal view); $c=$ coxal blades on leg I (ventral view); $\mathrm{d}=$ rallum; $\mathrm{e}=$ left palp (minus chela, dorsal view); $\mathrm{f}=$ left chelicerae (lateral view); $\mathrm{g}=$ left chela (dorsal view); $\mathrm{h}=$ leg IV (lateral view); $\mathrm{i}=$ leg I (lateral view). Scale bars: 0.25 $\mathrm{mm}(\mathrm{a}-\mathrm{b}, \mathrm{e}-\mathrm{i}) ; 0.20 \mathrm{~mm}(\mathrm{c}-\mathrm{d})$. 


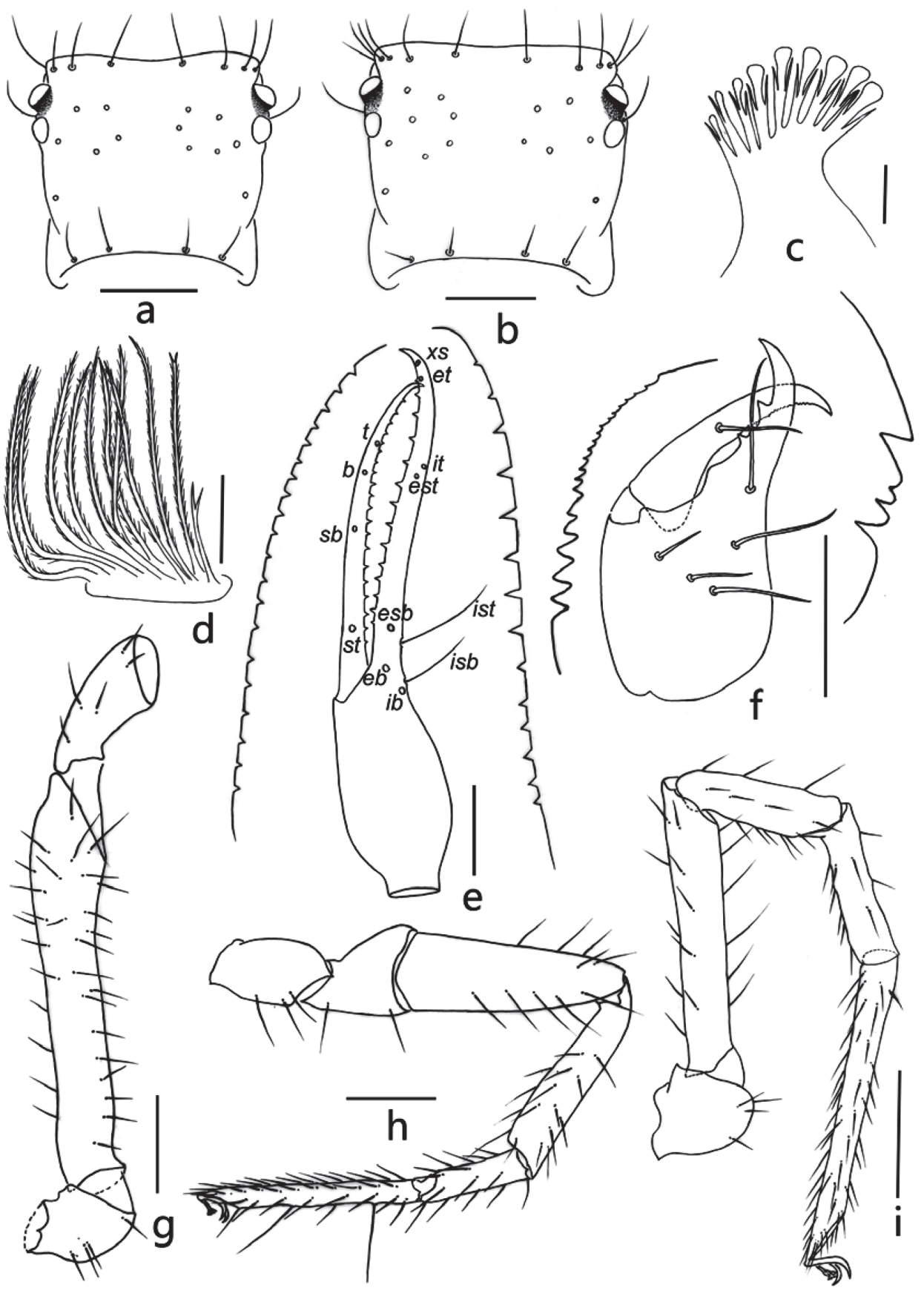


This new species is most similar to $A$. (A.) fuscus from China; after comparing the holotype of $A$. (A.) fanjingshan, we found the color of carapace and tergites are distinctly darker the that of $A$. (A.) fuscus which are mostly yellowish; the carapacal chaetotaxy are also different (8-6-6-2-4, 26 vs 8-4-4-2-4, 22); and $A$. (A.) fanjingshan has a larger body length (2.41 vs 2.25). This new species is also similar to $A$. (A.) sichuanensis which is also distributed in southwest China, but can be distinguished from the latter by the number of coxal blades

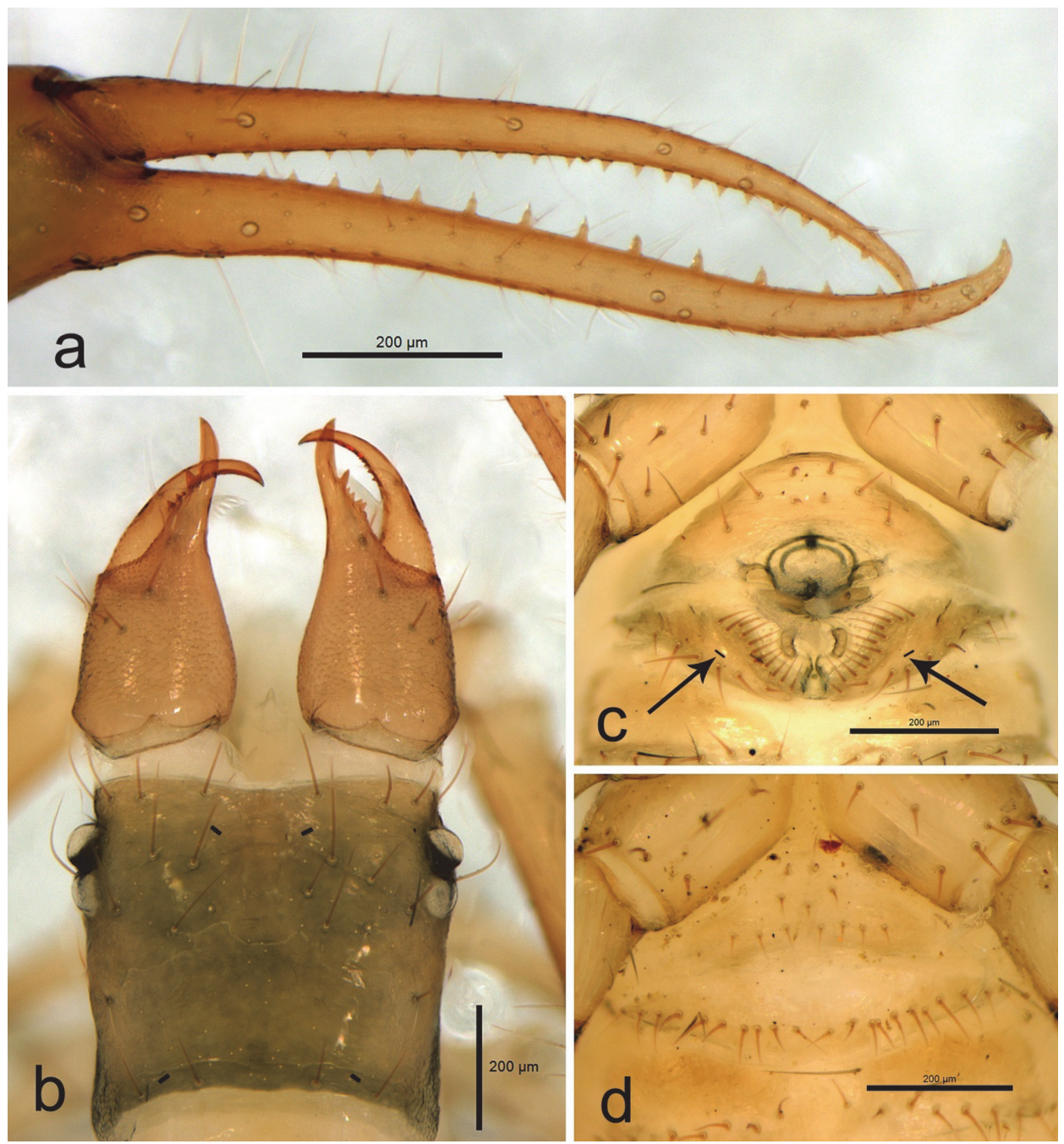

Fig. 6. Allochthonius (Allochthonius) fanjingshan sp. n.: $\mathrm{a}=$ left chela; $\mathrm{b}=$ carapace and chelicerae, position of lyrifissures indicated by black bars; $\mathrm{c}=$ genital area of holotype, position of lyrifissures indicated by black bars; $d$ = genital area of paratype (Ps.-MHBU-GZ14101203). 
present on coxa I, $A$. (A.) fuscus have 11 while $A$. (A.) sichuanensis only have eight; chelal femur of $A$. (A.) fuscus is somewhat stouter than that of $A$. (A.) sichuanensis (5.32 vs 5.6).

Description. Male. Carapace, abdomen, chelal hand slightly black, other parts pale yellow.

Carapace (Fig. 5a; Fig. 6b) subquadrate, somewhat shorter than broad (0.84 times), scarcely constricted posteriorly; anterior margin without denticulate; both pairs of eyes well-developed and large, with the lens vaulted; eyes almost $1 / 2$ diameter from each other, anterior pair of eyes one diameter from anterior margin of carapace; epistome absent, space between median setae straight or slightly recurved; chaetotaxy: 8-6-6-2-4, 26; with two pairs of lyrifissures, see Fig. 6 b.

Coxal area: tip of manducatory process with 2 setae, one long and the other short. Bisetose intercoxal tubercle present; coxal blades (Fig. 5c) only present on coxa I, consisting of a tubercle expanded terminally into a characteristic "spray" or "fan" of about 9 elevate processes which extend apically; setae P 3, I 4, II 5, III 6, IV 7.

Chelicera (Fig. 5f): almost as long as carapace; palm of chelicerae with 6 simple setae, bs short, a galeal seta located on the middle of the movable finger; both lateral sides of palm with fine granulations. Fixed finger with $4-5$ conspicuous teeth, one lyrifissures at the basal part; movable finger with 20 conspicuous teeth, the basal ones larger than the others; Serrula exterior with 17-18 lamellae; serrula interior with 16-17 lamellae. Rallum (Fig. 5d) in two rows and composed of 11 blades with fine barbules except the posterior one, which is shorter than the others.

Pedipalp (Fig. 5g): chelal hand robust, chelal finger straight in dorsal view; movable finger shorter than the fixed finger. Fixed finger with 15-16 acute teeth, which the middle

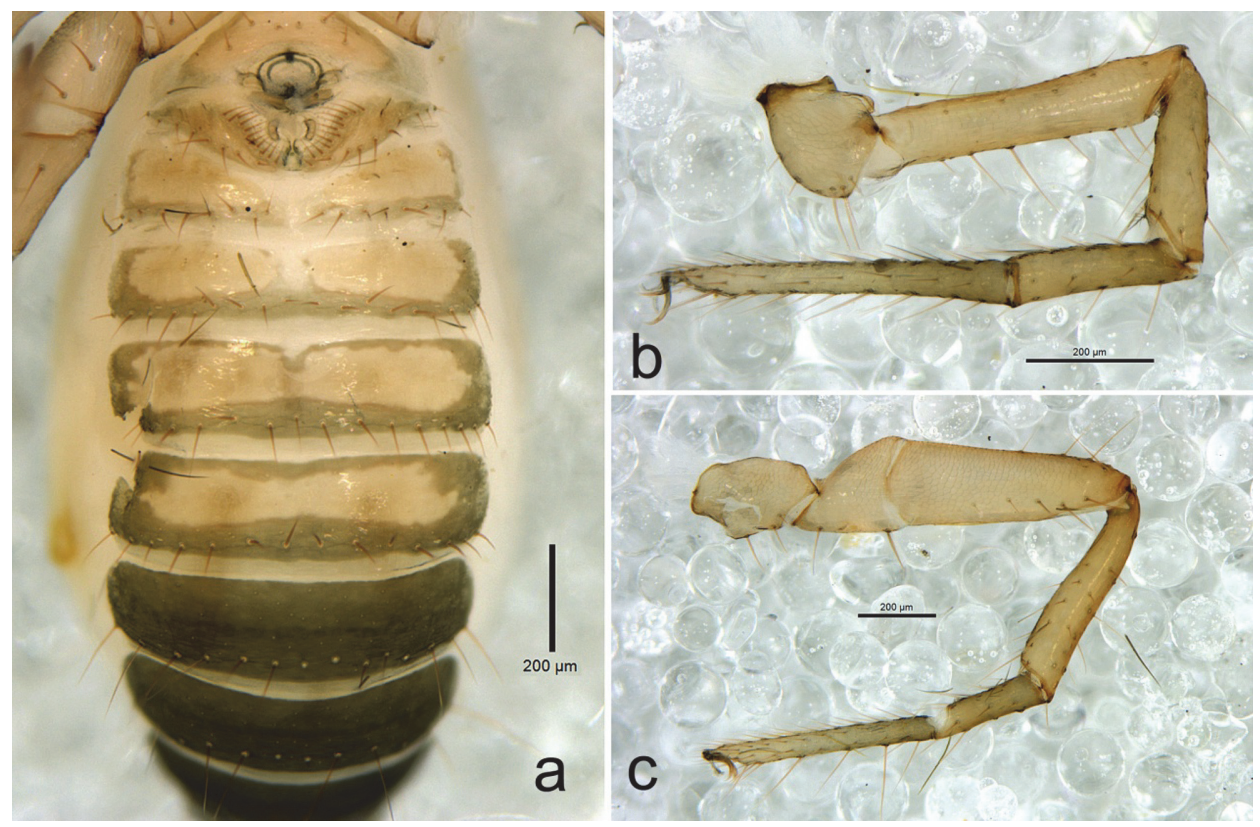

Fig. 7. Allochthonius (Allochthonius) fanjingshan sp. n., holotype: $\mathrm{a}=$ sternites; b = leg I; c. leg IV. 
ones larger than that in both ends; movable finger with 20-21 acute teeth, a tubercle between the tenth and eleventh. Trichobothrial pattern (Fig. 5e; Fig. 6a) typical: fixed finger with eight and movable finger with four; trichobothrium $s b$ indistinctly nearer $b$ than $s t$, est at level of $t$, line $i b$-isb-eb-esb-ist circled clustered at the base of fixed finger; in addition, two special sensory hairs (XS) present, which near the tip of fixed finger; sensilla absent.

Abdomen ovate, sternites III-VI with pale color area (Fig. 7a); tergites and sternites with numerous setae, tergal chaetotaxy I-XII $: 4: 6: 8: 8: 11: 11: 12: 14: 10: 10:$ TT $: 0$; anterior genital operculum with 8 glandular setae, genital opening pit-like in the basal half, each side with 12 marginal setae, 20 in total; sternal chaetotaxy III-X : $17: 17: 16: 14: 14$ : $12: 11: 8$; two lyrifissures present, see Fig. 6c.

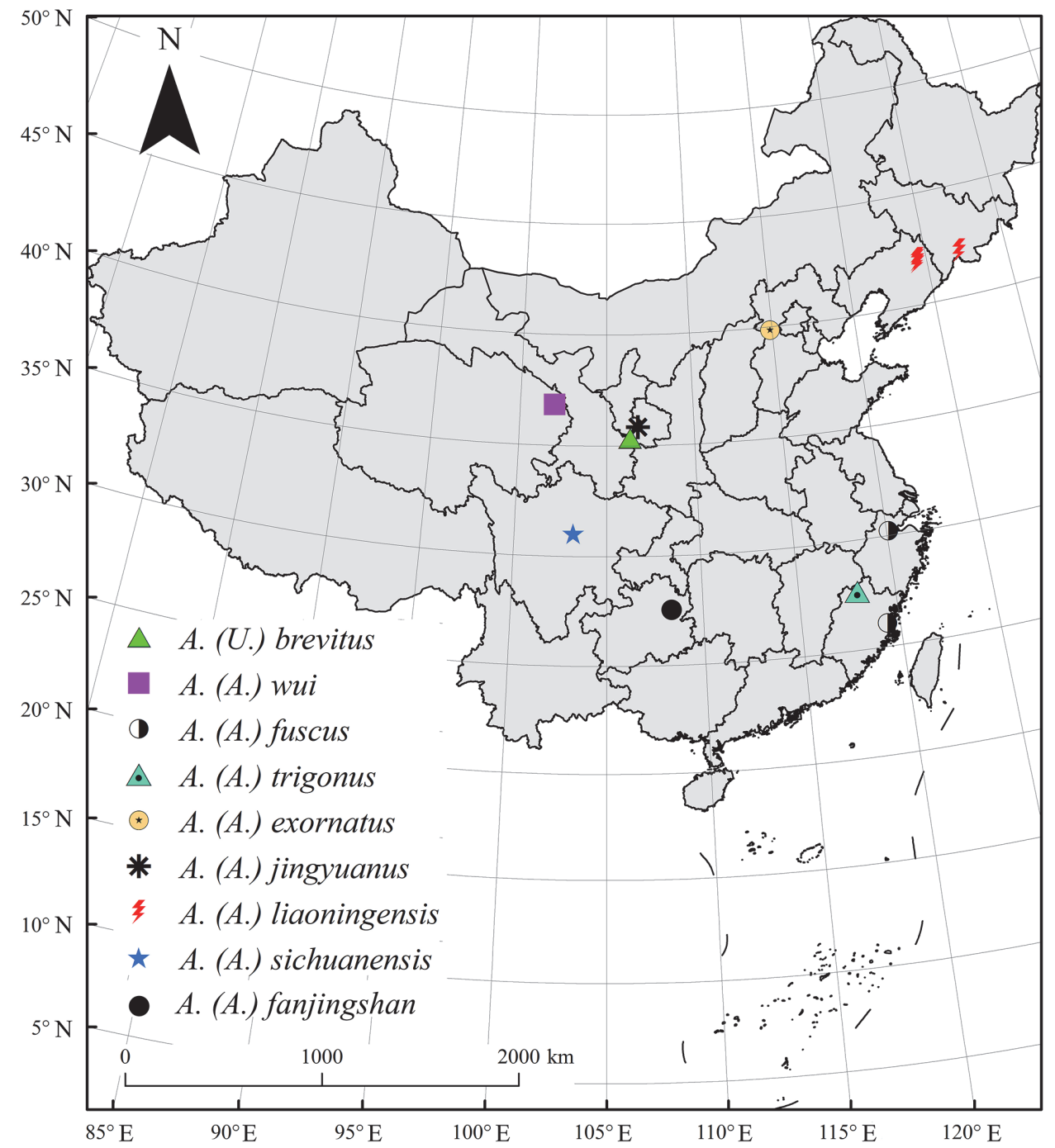

Fig. 8. The known distribution of genus Allochthonius from China. 
Legs (Fig. 5h-I; Fig. 7b-c) typical of family. Leg I and IV, trochanter and femur with squamous sculpture. Leg IV with a long tactile seta on tarsus (TS $=0.24$ ).

Brief description of female paratypes. Generally same as the holotype, anterior margin of carapace (Fig. 5b) with more setae (10-11); body length a little larger than the male; more setae present in anterior margin of carapace; chaetotaxy: ( (10-11)-6-6-2-4, 27).

Tergal chaetotaxy I-XII : $4: 6-7: 8-9: 11: 11: 11-13: 11-13: 13-14: 10-11: 8-9:$ TT : 0 ; anterior genital operculum with 12 setae, posterior margin with 20 marginal setae, 32 in total; sternal chaetotaxy III-X : $17: 17: 16-18: 16: 15: 12-14: 10-11: 10$.

Measurements (length/breadth or depth in mm, ratios in parentheses). Male. Body length 2.41. Carapace $0.49 \times 0.58(0.84)$. Palpal trochanter $0.26 \times 0.17(1.53)$, femur $1.01 \times$ 0.19 (5.32), patella $0.37 \times 0.15(2.47)$, chela $1.46 \times 0.29(5.03)$, palm $0.54 \times 0.29(1.86)$, movable finger length $0.88(1.63 \times$ palm). Leg I trochanter $0.21 \times 0.17(1.24)$, femur $0.57 \times 0.10(5.70)$, patella $0.32 \times 0.10(3.20)$, tibia $0.31 \times 0.05-0.08(3.88)$, tarsus $0.58 \times 0.06(9.67)$; leg IV trochanter $0.31 \times 0.19(1.63)$, femur+patella $0.87 \times 0.25(3.48)$, tibia $0.62 \times 0.11(5.64)$, metatarsus $0.30 \times 0.08(3.75)$, tarsus $0.58 \times 0.07(8.29)$.

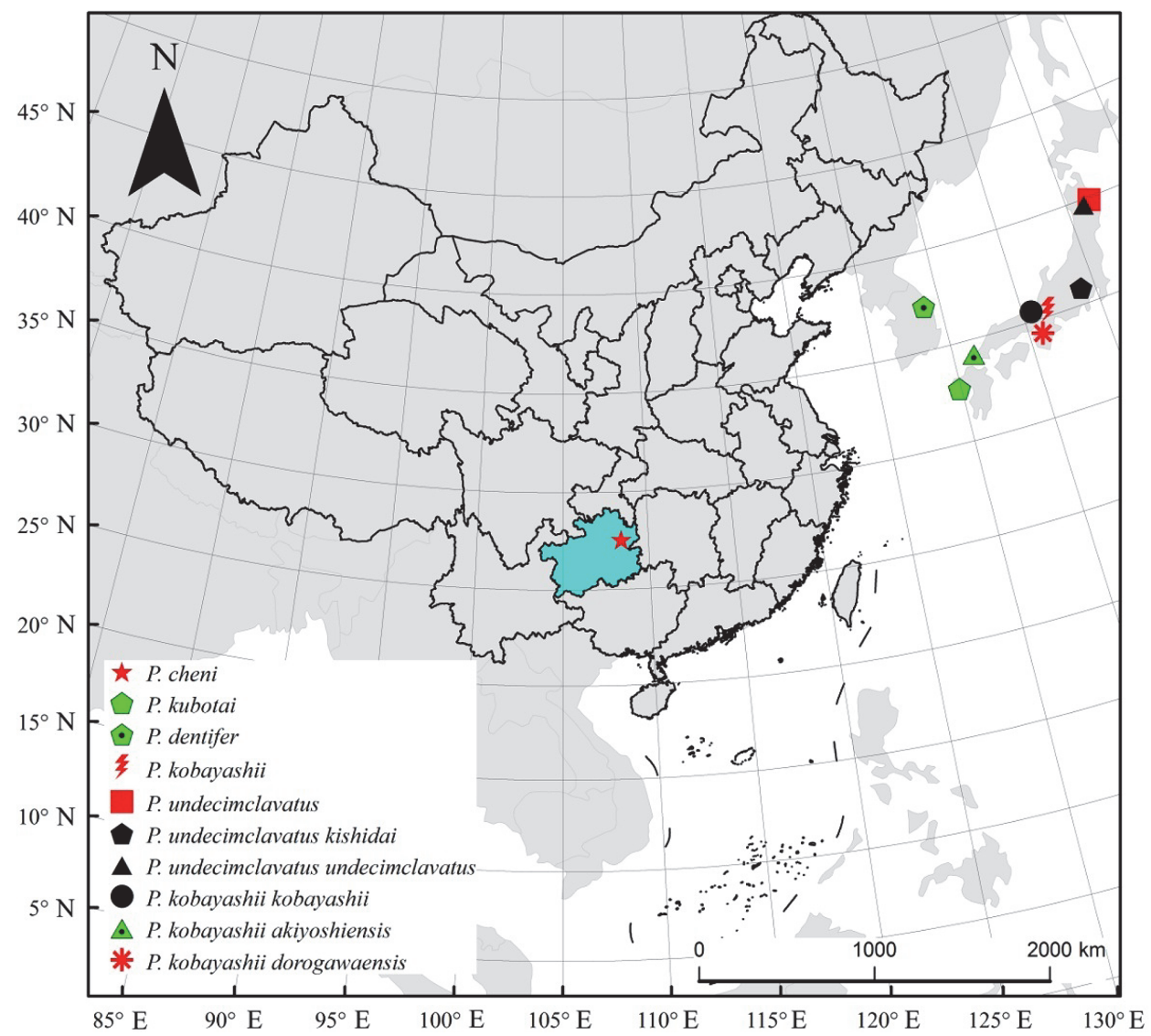

Fig. 9. The known distribution of genus Pseudotyrannochthonius in East Asia, Guizhou Province is highlighted. 
Female (paratypes). Body length 2.32-2.43. Carapace 0.54-0.57 × $0.72(0.75-0.79)$. Palpal trochanter $0.29 \times 0.19-0.21$ (1.38-1.53), femur 1.13-1.16 $\times 0.19-0.21$ (5.52-5.95), patella $0.43-0.45 \times 0.20(2.15-2.25)$, chela $1.62-1.68 \times 0.39-0.42(4.00-4.15)$, palm $0.57-0.60 \times$ $0.39-0.42$ (1.43-1.46), movable finger length $1.02(1.70-1.79 \times$ palm). Leg I trochanter 0.23 $0.25 \times 0.18-0.19(1.28-1.32)$, femur $0.59-0.61 \times 0.11-0.12(4.92-5.55)$, patella $0.35 \times 0.10-0.11$ (3.18-3.50), tibia 0.32-0.34 × 0.08-0.09 (3.78-4.00), tarsus $0.62 \times 0.06-0.07(8.86-10.33)$; leg IV trochanter $0.21-0.26 \times 0.19-0.20(1.11-1.30)$, femur+patella $0.92-0.94 \times 0.25(3.68-3.76)$, tibia $0.67-0.68 \times 0.13-0.14(4.79-5.23)$, metatarsus $0.32-0.33 \times 0.08-0.09$ (3.67-4.00), tarsus $0.64-0.66 \times 0.07(9.14-9.43)$.

Distribution. China (Guizhou).

Habitat and ecology. Same as that of Pseudotyrannochthonius cheni sp. n.

Acknowledgements - We are grateful to Dr. Huiming Chen (Guizhou Academy of Sciences, Guiyang, China) for kindly assisting with the field work. Many thanks are given to Prof. Zhisheng Zhang (School of Southwest University, Chongqing, China) for inviting us to join this survey. Dr. Xun Bian (College of Life Science, Hebei University, Baoding, China) is thanked for the help in distribution maps making; helpful comments on the manuscript were provided by two anonymous referees. This work was supported by the National Natural Science Foundation of China (Grant No. 31372154, 31093430).

\section{REFERENCES}

Beier, M. (1930) Alcuni Pseudoscorpioni esotici raccolti dal Prof. F. Silvestri. Bollettino del Laboratorio di Zoologia Generale e Agraria del R. Istituto Superiore Agrario in Portici 23: 197-209.

Beier, M. (1932) Pseudoscorpionidea I. Subord. Chthoniinea et Neobisiinea. Tierreich 57, $258 \mathrm{pp}$.

Beier, M. (1966) On the Pseudoscorpionidea of Australia. Australian Journal of Zoology 14: 275-303. http://dx.doi.org/10.1071/ZO9660275

Benedict, E. M. \& Malcolm, D. R. (1970) Some pseudotyrannochthoniine false scorpions from western North America (Chelonethida: Chthoniidae). Journal of the New York Entomological Society 78: 38-51.

Chamberlin, J. C. (1931) The arachnid order Chelonethida. Stanford University Publications, Biological Sciences. 7: 1-284.

GAO, Z. Z. \& Zhang, F. (2013) Description of a new Allochthonius species from China, with a key to the genus (Pseudoscorpiones Pseudotyrannochthoniidae). Entomologica Fennica 23: 107-112.

Harms, D. (2013) A new species of Pseudotyrannochthonius Beier (Pseudoscorpiones: Pseudotyrannochthoniidae) from the Warrumbungle Range, New Sourth Wales. Memoirs of the Queensland Museum | Nature 58: 23-32

Harms, D. \& Harvey, M. S. (2013) Review of the cave-dwelling species of Pseudotyrannochthonius Beier (Arachnida: Pseudoscorpiones: Pseudotyrannochthoniidae) from mainland Australia, with description of two troglobitic species. Australian Journal of Entomology 52: 129-143. http://dx.doi.org/10.1111/aen.12009 
Harvey, M. S. (1992) The phylogeny and classification of the Pseudoscorpionida (Chelicerata: Arachnida). Invertebrate Taxonomy 6: 1373-1435. http://dx.doi.org/10.1071/ IT9921373

Harvey, M. S. (2013) Pseudoscorpions of the World. Version 3.0. Western Australian Museum, Perth. http://museum.wa.gov.au/catalogues-beta/pseudoscorpions (accessed 26 April 2015).

Hu, J. F. \& ZhANG, F. (2011) Description of three new species of the genus Allochthonius Chamberlin, 1929 (Pseudoscorpiones: Pseudotyrannochthoniidae) from China. Journal of Threatened Taxa 3(11): 2167-2176 http://dx.doi.org/10.11609/JoTT.o2767.2167-76

Hu, J. F. \& ZHANG, F. (2012) Two new species of the genus Allochthonius Chamberlin from China (Pseudoscorpiones: Pseudotyrannochthoniidae). Entomologica Fennica 22: 243248.

Judson, M. L. I. (2007) A new and endangered species of the pseudoscorpion genus Lagynochthonius from a cave in Vietnam, with notes on chelal morphology and the composition of the Tyrannochthoniini (Arachnida, Chelonethi, Chthoniidae). Zootaxa 1627: 53-68.

Morikawa, K. (1960) Systematic studies of Japanese pseudoscorpions. Memoirs of Ehime University (2B) 4: 85-172.

Muchmore, W. B. (1967) Pseudotyrannochthoniine pseudoscorpions from the western United States. Transactions of the American Microscopical Society 86: 132-139. http:// dx.doi.org/10.2307/3224679

Zhang, F. B. \& Zhang, F. (2014) A new species of the genus Allochthonius (Pseudoscorpiones: Pseudotyrannochthoniidae) from Liupan mountains, China, with description of the male of Allochthonius brevitus. Acta Zoologica Academiae Scientiarum Hungaricae 60(1): 45-56.

Received March 3, 2015, accepted July 18, 2015, published May 6, 2016 


\title{
The oribatid species described by Berlese (Acari)
}

\author{
by MAHUNKA, S. and L. MAHUNKA-PAPP
}

The authors had the opportunity for years to study the Oribatid species described by Berlese currently deposited in the Istituto Sperimentale per la Zoologia Agraria at Florence. The results of this series of studies are summarized in this volume.

The volume begins with an essay-like Introduction heavily relying on subjective opinions discussing the general questions of Oribatology. The following section lists Berlese's species placed in the modern system helping the specialists with morphological notes and many drawings; here also the condition of the specimens is discussed and lectotypes are designated.

The third, large section is the catalogue proper, wherein all the species are listed in the systematic order together with their combination and synonymic names. Here one may find all the literature data, usually missing from ordinary works, with reference to Description and Taxonomy, Distribution, with special emphasis on Catalogues whose references are partly unreliable. Where it was deemed necessary further information are added under the heading of Remarks. The volume closes with a very detailed list of literature.

ISBN 9637093273

325 pages with several figures. Soft bound.

Hungarian Natural History Museum, Budapest, 1995

Price: 40 US dollars excluding package and postage

Order should be sent

to the Hungarian Natural History Museum, Library

Baross u. 13, Budapest, H-1088 Hungary

Fax: (36-1) 3171669 